\title{
Learning From Our Mistakes: What Matters When Incorporating Blogging in the Content Area Literacy Classroom
}

\section{The need to integrate}

technology into the

curriculum for preservice

teachers comes with its

own set of challenges. By

sharing our struggles with

integrating blogging into

our own classrooms, we

hope to both encourage

and inform educators

interested in making their

classrooms technology-rich

environments.
Holly Hungerford-Kresser | Joy Wiggins | Carla Amaro-Jiménez

Like I said, the blogs were not a factor in me learning anything really. The textbook and the classroom activities were but the blogs were not. (Anonymous focus group participant)

In the digital age of Facebook, Twitter, Wikis, and blogging, it seems only natural to integrate digital literacies in preservice teacher education programs. We chose blogs as a pedagogical tool in our content-area literacy classes for preservice teachers, hoping to help them engage in discussions that were closely aligned with the course content while building classroom communities.

The blogging project was borne from a Quality Enhancement Program (QEP) with funding received by the first two authors. As part of the project, a longitudinal study (two and a half years) was carried out on the effectiveness of integrating blogs into our content literacy classrooms. Though we have rarely read published studies on projects that were deemed "failures," this is what our project appeared to be.

As we studied the quantitative results semester after semester, the blogs statistically had no measurable impact on students' perceptions of the course or content literacy. Granted, students were generally pleased with the content of the course, but there was no statistical significance found in relation to the blogging itself, no matter what was done to try and make the blogs more useful to students. In fact, students typically cited the blogs as the least important tool in their learning the course content.

As teachers, however, we had absorbed the discourses (Fairclough, 2001; Gee, 1999) surrounding technology and the classroom, and we were curious about why students did not respond well to the blogs. We assumed that this generation of tech-savvy students would enjoy this particular medium for discussing their reading. After all, weren't these the students who were supposed to love any sort of technological intervention? Weren't these supposed to be the students who were anticipating the myriad ways that they could incorporate technology into their future content classrooms? 
With our study now complete, we decided to contextualize the quantitative data we collected by looking at qualitative data-namely the blogs, the focus group transcripts from each semester, and reflective memos (Creswell, 2009) that were written every semester to document the successes and challenges of the project. The new research questions centered on preservice teachers' responses to the integration of blogging in their content literacy courses and the pedagogical implications these responses would have for teachers interested in new literacies in classrooms. Thus, in this article we share student responses and opinions about blogs, and preliminary lessons learned for instructors who might someday want to incorporate particular technologies in their courses.

\section{Perspectives: Blogging as a Tool for Facilitating Communities of Practice}

Our work is broadly situated in sociocultural theories of teaching and learning, which posit that learning occurs in a context of shared practice (Rogoff, 1995). This context of shared practice is facilitated when communities of practice $(\mathrm{CoP})$ are created. These $\mathrm{CoP}$ allow not only for the co-construction of knowledge between experts/novices and novices/novices in the community (Lave, 1996; Rogoff \& Lave, 1984), but also provide opportunities for all involved to examine the learning that takes place. This concept is central to our practice, pedagogy, and research.

At the same time, the integration of technology into teacher preparation programs is presented as an urgent need and as a requirement of successful preparation programs (National Associatiom for the Education of Young Children, 2002). Scholars have studied digital pedagogies as tools to create and foster CoP (e.g., Beckett, Amaro-Jiménez, \& Beckett, 2010; Lin, 2008).

In fact, it has been argued that at least $55 \%$ of U.S. institutions have implemented some sort of computer-mediated communication (CMC) into existing courses already (Allen, Seaman, \& Garrett, 2007). Thus, based on our desire to give our students opportunities to participate in $\mathrm{CoP}$ while also minding our university's mandate to integrate technology into all of our courses, we attempted to strengthen CoP in our courses by using Web Logs (blogs) as the instructional tool.

In its broadest sense, a blog can be considered an online journal, one in which an author writes, edits, and makes its content public (or not) without requiring extensive knowledge of Web programming or design. Blogs are an interactive form of CMC that allows students to converse asynchronously via a forum on the Internet.

Blogs allow students to post text and share hyperlinks, images, and multimedia in addition to creating their own threads of conversation. Asynchronous tools can help create a medium for students to provide feedback to one another, hold a discussion with or without the instructor present, and foster a collaborative learning environment (West, 2008). In addition, instructors can post notes, links, and resources for all students to view (Green, Brown, \& Robinson, 2008).

Accounts of the benefits of blogging have begun to appear in the literature as more classroom teachers and teacher educators have begun to incorporate them as instructional tools. Kist (2008), for example, described how a teacher who works with very young children resorted to creative ways in order to document the hatching of chicks in her classroom. In this kindergarten teacher's case, she created a class blog and has blogged on behalf of her students to increase their opportunities for language development.

West (2008), a high school teacher, created a blogging project for her 11th-grade American Literature class. As part of the project, West investigated the extent to which students were able to create hybrid and situationally embedded identities in the blogs; as her research showed, these were identities that were shaped by the blogs themselves, her students' reactions to the texts they read, and a variety of events in the students' lives. By drawing on three of her students' blogs, she demonstrated that while the students considered the blogs as an informal outlet to discuss and share their views, they were able to deepen their knowledge of what they were 
learning in school and also draw on what they knew about acceptable school discourses and norms.

To this end, researchers have suggested that when blogs are used as part of one's coursework, as was the case in this study, students can be given opportunities to connect what is being learned in the classroom with what is being discussed in the blogs. In fact, Yang (2009), who analyzed the blog contributions of 43 English as a foreign language teachers in two teacher education programs, suggests that the use of blogs not only enhanced the teachers' learning of course content, but that through their use they were able to create a CoP where people shared their opinions and the challenges and strengths they felt as educators, all while feeling supported by one another.

Johnson's (2010) findings also support those by Yang (2009), as her use of blogs in a teacher preparation program allowed her students to get to know their peers both personally and academically when they interacted on the blogs. Moreover, Johnson argued that by having pre- and in-service teachers analyze other authors' blogs, they can not only develop a more close connection to those who write the blogs, but also think about ways in which they can, as teachers, do the same in their own classrooms to benefit their students. In other words, she argues that through reading other people's blogs and writing their own, students' learning can be greatly improved.

These studies all suggest that by integrating new literacies in general, and blogs in particular, in the classroom requires new skills and strategies that prepare students to access and contribute information to a world-wide knowledge base. It is argued that by integrating these tools in preservice teacher programs, teachers are able to bridge the gap between out-ofschool literacies and in-school literacies (Alvermann 2005). By using tools like blogs, students are learning how to critically evaluate what they read and to recognize the ways in which they read information from the Internet. There is a push, particularly in the field of critical literacies, to encourage students to examine the many voices contained in this ongoing, constant surge of information in the age of technology (Gorski, 2005).

It is thus suggested that technology can "actively engage students in their own learning, encouraging the exchange of critical questions and thought, and expanding students' understandings of various issues by supplementing textbook learning with first-person international and intercultural perspectives and ideas" (Gorski, 2005, p. 70). However, as he also argued, it is up to the teacher or instructor to encourage students to take advantage of these learning opportunities.

Moreover, Alvermann (2008) reminded us that incorporating digital pedagogies into our teaching, whether it is in $\mathrm{K}-12$ or higher education, must directly respond to students' interests and needs. She argued that gathering input from the students themselves about the use of these tools and their integration into the courses will yield information related to the expectations, hopes, and shortcomings that they may foresee, which are key pieces of information for those who need to make them an integral part of their teaching.

We believe the literature offers ample reasons to attempt blogging with preservice teachers, but there was not much in the way of longitudinal studies on blogging with future teachers. Additionally, we thought an ongoing study would give us more time to troubleshoot issues and find ways to make blogging effective, so we blogged for multiple semesters.

However, based on our work, we know that the integration of technology is not always a smooth process, even for experienced instructors. Logically, we can assume these sorts of difficulties will also be true for our preservice teachers as they move into the classroom as novices. This is what our study has to offer the literature-struggles and suggestions, an honest account of our attempts, one substantiated in research.

\section{Our Study}

This study is a follow-up to a two and a half year longitudinal mixed methods study that began in spring of 2008 and ended in fall of 2010. We explored the impact of blogging as a means of facilitating CoP in Holly's (first author) and Joy's (second author) content literacy classes. Each semester, there was a control group (Holly's class) and an experimental group (Joy's class), randomly determined by students' enrollment in either section. The experimental group was required to use blogs regularly as part of class participation, while the control group did not. 
Though there were two instructors, we planned together and made sure that all other elements of the course were as close to identical as they could be, including syllabus, assessments, rubrics, textbook, and major assignments. We (incorrectly) assumed that the blogs would be a popular option with students, and offered little in the way of direct instruction for preparing blog responses outside of clear criteria for what should be included. Ample examples were given, (e.g., Joy's blog), but any additional instruction occurred one-on-one.

The blogs were graded as part of students' overall participation grade. The blogging requirements were changed slightly from semester to semester based on the student survey responses we received. The requirements for the blog were an open response to the readings. Centered on their textbook readings, topics were indicative of the chapters students were reading, such as: "Language, Diversity and Culture," "Creating a Favorable Learning Environment," and "Increasing Vocabulary and Conceptual Growth" (Alvermann, Phelps, \& Gillis, 2006).

Initially, students created their own blogs and visited three other blogs per week. This was complicated and difficult to follow. We then decided to create one class blog. Students were required to respond at least once and reply at least once a week. Additionally, in the third semester of data collection, we also changed the format of the required response. First, they would write where they saw a particular concept in the chapter represented in their own educational experience (or not); second, they were to write how they would have liked to have seen this concept in their experience; and third, they would consider how they would implement this idea in their future teaching. We were attempting to make the blogs more of a factor in students' learning, but with each alteration, nothing changed statistically.

\section{Participants and Content Literacy Classes}

All students in our courses participated. Two sections were offered every semester (fall and spring); a maximum of 45 students were enrolled in each section. There were two summers of data collection: the first summer was an experimental group where blogging was included, and the second summer was a control group where no blogging was integrated. Our courses meet once a week, in the evenings and last three hours, with the exception of summer, where students meet twice a week for four hours each time.

The content areas represented each semester included kinesiology, music, art (K-12), and English language arts, history, math, and science (secondary). The students were juniors and seniors, all pursuing teaching certification, and the section was a required educational course to be taken before graduation.

\section{Data Collection}

Each semester, an assessment assistant from the university's QEP research team helped with data collection specific to the larger university-wide active learning research initiative. We predominately highlight focus group data in this study. Focus groups were held for each course section at the conclusion of each semester. These focus group discussions involved six to 10 students from each section of the class. The students, led by a counselor from the Office of Student Counseling, anonymously responded to questions about how the course was delivered and, as appropriate, about the impact of blogging on student learning.

Focus groups were transcribed verbatim, in their entirety, and all student participants were kept anonymous. We collected all of the transcripts from the student focus groups, and the blogs from each semester were archived. As participant researchers, we also filled out reflective memos (Creswell, 2009; Merriam, 2002) at the end of each semester, which allowed us to summarize the semester's teaching; these reflection memos were supplemented by meetings with the university's QEP research team at the end of each semester to review the raw data and discuss the semester.

\section{Data Analysis}

Because of our regular meetings with the QEP research team, we were already familiar with the quantitative data (e.g., survey data collected through 
IDEA forms) and therefore decided to focus strictly on the qualitative data once the study finished. We created new research questions for the qualitative study: (a) What were students' perceptions of the learning that occurred on the blogs? and (b) How did the blog archives refute or support these perceptions?

In this study, we focus exclusively on our first research question. We used NVivo software and constant comparative analysis (Creswell, 2009; Lincoln \& Guba, 1984) to code the focus group transcripts. We categorized student responses into six categories: (1) classroom environment, (2) instruction, (3) negative opinions on blogs, (4) positive opinions on blogs, (5) opinions for improving blogs, and (6) blogs' impact on learning.

We then took categories three through six and coded them more distinctly, using the students' actual verbiage. For example, one code under category three was "Worthless/Waste of Time," because this was a common complaint from students. We looked at the codes that came up the most frequently and those are the focus of the findings we detail in this manuscript.

Overall, this qualitative analysis supported what the quantitative data analysis revealed: There was virtually no difference in the way students viewed the class, based on blogging as the intervention. Students generally enjoyed the class, and what they felt they learned typically aligned with our instructional goals, but they did not attribute any of this success to the blogs. In fact, they generally felt the blogs were "just another thing to do" (Focus Group Participant, Spring 2008).

What follows are themes based on student opinions of the blogs. Each of these themes was repetitive and consistent throughout data analysis, and we have chosen quotations we feel to be representative of multiple students' opinions to better explain what occurred. We triangulated each theme by analyzing blog responses and studying the quantitative results. Because of space limitations, we have opted to highlight the focus group data, as it clearly demonstrates our "mistakes" and offers the best information for practitioners and researchers both in and outside of the field of content literacy.

\section{Learning From Our Mistakes}

\section{Blogs: Just Another Task}

As the quotation we used to introduce the manuscript intimates, the most common response to the blogs was that they were worthless or useless, or simply a hassle to participate in. Many students in the focus groups identified the blogs as just another task to complete, rather than a benefit or preference for communicating in the class. One student explained,

It's worthless for me...I mean, I'm going to go about 5 minutes before class starts and put my response in...I think it's a good idea, I just don't know if it's doing its job...it doesn't serve any purpose really, and yeah, I don't understand the point really. (Focus Group Participant, Fall 2008)

Whether using the phrase "worthless" like the student previously, or "useless" as another student suggested, generally students did not see the purpose behind the blogs. They would argue that the blog too closely resembled other assignments or tasks, like the reading response journals, or they would leave the comments broad by saying they "didn't understand the point."

Either way, not a single student over the course of the study pointed to the blogs as an effective pedagogical tool or pointed to a purpose for it that was unique. We had hoped blogs would help foster a learning community or a $\mathrm{CoP}$, but the reality is that for most students, the blogs were a task, not a way to build community.

\section{Participation Tracker, Not a Conversation Starter}

In digging more deeply into focus group responses, students made it clear that they felt the blogs did little more than check their participation in the course. The following quotation demonstrates what we often heard from students:

I think it was useless...you got your participation points and she (Joy) would explain to us that it's supposed to be discussion but there was no discussion...it was just 20 posts of just "here's what I think" there was no like "so I feel... I agree with such and such because..." or "what do you guys think?" There was no interaction; just comments. There was no flow... so I think it was useless. (Focus Group Participant, Fall 2008) 
At the same time, students often felt that the blogs too closely resembled other classroom activities, and therefore were repetitive and dull. They often stated they wanted the blogs to facilitate more deep conversation, but were unhappy with how they played out: "It's just a response, it's not a conversation; it's just a response..." (Focus Group Participant, Fall 2008). In Fall 2009, a student explained,

I'd feel like after so many people have already blogged, by the time you maybe get to blogging, everyone's already said everything you think so you sort of sit there and you're like, "Well, what can I write to be original?" because that's exactly what I think so I probably do agree with maybe a prompt or an actual personal question of the class...

Many students echoed this concern. They worried about being able to come up with "unique responses" or things that other folks had not yet said, but felt in such a large discussion this was almost impossible. Thus, in addition to the pressure of getting a response in on time, there was the added pressure of "being original," which added to their overall discontent with blogging.

\section{The Tech-Savvy Student Versus the Technologically Apprehensive Student}

In the focus groups, students would often begin their responses with statements that allowed us to label them "tech savvy" or "technologically apprehensive." In data analysis, it became interesting to us to note the differences in responses for students who considered themselves tech savvy and those who were more apprehensive.

Often the students who considered themselves comfortable with technology would comment about less technologically savvy students: "Maybe for those students that are struggling to stay up with the latest technology, maybe forcing them to use those mediums would help them to become more technologically savvy" (Focus Group Participant, Fall 2008). The technologically apprehensive students often spoke about the classmates they felt were more competent with technology and usually did this in order to compare themselves to the others. Because we serve many nontraditional-aged students on our campus, often these differences were highlighted in terms of age:

I'm much, much older than most of the students in the class. I did not grow up in school where there were even computers in the school room so I was panicked. I was not comfortable with blogging and not even knowing how to do it. I just wasn't comfortable with it at all until I realized it was not as difficult as I had anticipated. Once I got into it Students often felt the blogs too closely resembled other classroom activities.... Participant, Spring 2009)

With every focus group participant who claimed to not be comfortable with technology, they always followed their statements by somehow indicating a level of comfort with blogging once the course ended. We did not see any comments that suggested a real interest in continuing to blog or using it in the future classroom, but there was more comfort with it at the conclusion of the class.

I am not so technically savvy and so I freaked out. I thought, "What am I going to do? People on the Internet are going to see what I write. You know, I have to be so careful." And I hated it at first. I didn't want to do it and when I got more comfortable with it and started reading other people's blogs, it became fine. I wasn't so terrified of it. (Focus Group Participant, Spring 2009)

Interestingly, there was an almost opposite reaction from students who considered themselves tech-savvy. Many of the students who were comfortable with blogs coming into the class were disappointed with what the blogs offered them in the class. While they had hoped for conversations and opportunities to get to know classmates, this often was not what happened.

One student explained,

I've been blogging one way or another for years and years and years, but it was still just one more thing to do... I would like to use the blogs as a medium to really point out my concerns for the class and issues I am struggling with. (Focus Group Participant, Spring 2009) 
Many of the student comments thus far demonstrate students' opinions about the potential for blogs. In the sections that follow, we highlight student suggestions for improving the impact of blogs in the classroom.

\section{Blogging: What Matters?}

With our study concluded, we have only just begun to (re)conceptualize our data in light of these findings and uncover some suggestions for practitioners who are considering blogging in their classrooms. While we know that blogs, like many other asynchronous tools being used in the classroom (Lin, 2008), can potentially facilitate learning and extend students' thinking, data shared here demonstrates that, at least in our classes, the way we had it structured did not do this.

Students, in addition to telling us what the issues were with the blogs, also frequently offered suggestions for improving blogging as a tool in their classrooms. We have combined their thoughts with some of our own preliminary suggestions in order to offer some options for practitioners interested in pursuing blogging in the classroom. It is important to note that these suggestions are based on our research, and not yet verified in practice. They signify the ways we will attempt to modify blogging in our courses with preservice teachers. We will implement these suggestions into our own teaching over the coming semesters and will study the impact of these modifications.

\section{More Instructor Guidance, Perhaps?}

Generally, students liked the instructor's personal blog. Joy's blog was used to post sample assignments, class information, PowerPoint presentations, and notes for class. Many students felt this was helpful and a good use of a blog:

The blog, it was good to go there. I went there a lot because she has a lot of student work examples and I really appreciated that and there was some good information she would post, you know, links to other interesting things. (Focus Group Participant, Fall 2008)

In addition, students often stated they wanted more instructor input on the blog conversations.

However, Joy (second author) felt that each time she attempted to integrate herself into student blog discussions, the blogs "immediately shut down"
(Reflective Memo, Fall 2009). Based on this, we argue that instructors need to work to achieve balance between participation and student autonomy, between using the blogs to disseminate information and in guiding discussions.

While we obviously have not yet found this balance, it could be achieved. Doubtless this would look different for different instructors in different classes and based on student needs. One important note is that we did not delve deeply into our students' opinions and needs until the study ended, which makes us believe it is imperative to gauge student responses as courses/classes proceed.

Elements of action research (Hubbard \& Power, 1999) seem necessary to the successful implementation of blogs, but it was not merely enough for us to collect data as we went. We needed to spend time analyzing data (particularly the qualitative) as we taught our courses and extended our study.

We (still) believe that blogs are a good starting place for students to discuss issues they may not feel prepared to talk about in class, especially when they have little direct knowledge of the issue or topic. Overall, we would suggest analyzing blog responses throughout, even if an instructor is not always participating in the conversations students are having. To do this, then we suggest identifying a given number of main points, ideas, or issues that were solely discussed on the blogs, and then having the instructor use these as part of the class discussion.

These "key points" could be used by the instructor to either complement the class' discussion as he or she sees fit, or to open up new questions for discussion both in class and on the blogs. Bringing those conversations back to the classroom would help to make learning more explicit to students, and hopefully would make them less likely to see the blogs as another task to complete, rather than a potentially helpful medium for expressing themselves.

\section{Need for Topics/Prompts}

Students clearly articulated a need for the blogs to be different from other class tasks. They wanted to see purpose in the blog assignments. It is important to reiterate that students in our courses were blogging in response to their reading, responding to particular chapters. As such, they often suggested prompts or 
topics as a method for dealing with making the blogs less laborious:

Everything on the blog was exactly what was showed to us in class.... I think maybe we should have had something else, like a question for discussion, you know, a posted question that maybe would have helped the interaction a little more. (Focus Group Participant, Fall 2008)

Another student in the following spring (2009), explained, "I think it would be better if we had a prompt we could answer or talk about...." As instructors, we see the validity in these arguments.

As mentioned previously, blogs could potentially be more than just a platform to engage in discussions; students could use this as a medium where they can do more than scratch the surface of topics. To do so, one possibility is to frame discussions around students' interest in the topic, rather than simply limiting discussions by timeframe. That is, blogs could be seen as ongoing conversations in which a topic is discussed for as long as there is interest, rather than just by the period of time when the topic is discussed in course materials.

These blogs could thus be created or organized around key topics rather than by specific time periods, and the instructor could move on when the topic loses momentum. This would also allow students to make connections across topics and would be a visual/verbal reminder of their membership in a CoP.

\section{Smaller Discussion Groups}

On rare occasions throughout our study, students did have positive comments about blog participation. This typically occurred when they found a thread of conversation that interested them, often something that deviated from the prescribed blog format for the class:

I think the blogs have been interesting at times when people have actually taken time to sort of read what other people have said and respond to it. I think some of the most interesting blog entries ended up being with us kind of bantering back and forth between other members of the class... it was something different because we've all kind of fallen into the pattern of "I found today's class really interesting. The literacy strategies were great." (Focus Group Participant, Spring 2009)
The kind of banter that this student is discussing is difficult to discover in large classes with all students participating on a single blog. As we noted earlier, our classes always have 40 or more students. In retrospect, and in carefully considering these comments, we have come to the conclusion that smaller, rotating blog groups will be our next step. It allows students more intimate levels of conversation and Blogs could potentially be more than just a platform to engage in discussions.

possibilities for connection.

In addition, it gives them ample opportunity to spend time getting to know other students in their class, hopefully creating community. This could be structured with multiple small discussion groups with a variety of topics posted, or students could join smaller discussions based on the topics themselves. We are considering trying each option in one of our sections and comparing the results.

\section{Encouraging a Variety of Responses}

With this experience behind us, in the future, in part to avoid the characterization of blogs as "just another thing to do," we would carefully model thoughtful responses from students; but we would allow these responses to take on a variety of formats. In addition to enhancing our students' experiences as students, we feel that this is also important to model for them as future teachers.

We frequently speak to our classes about the importance of helping students to become conscious of their own learning. But in this case, we really failed to model for our own students. We now recognize that some students would prefer to express themselves in a variety of modes.

In the future, we hope that including podcasting (audio streams), vodcasting (video streams), and wikis (collaborative pages about specific concepts learned in class) would be another way to capitalize on the multiple learning styles represented in our classes (and in our future teachers' classrooms as well). These resources could then be added and shared on the blog. Students with less of a technological background could be encouraged by the variety 


\section{Take Action:}

1. Take note of student needs and insert (or remove) yourself from blog discussions accordingly. If it seems they need more direction, offer it. If your presence seems to "shut down" discussion, then leave it to the students.

2. Incorporate blog discussions into face-to-face class time. Let students know you hear what they are saying on the blogs. (e.g., "In reading blog posts, I have noticed many of you feel you need more concrete examples about incorporating strategies for ELs. I will help you by....”)

3. Organize blogs by key topics, and let students decide when those topics are exhausted. This keeps students from being limited by what you feel they need and allows for ongoing assessment.

4. Use smaller blog groups for discussions. While whole-class blogs have their own purpose, smaller blog groups will allow students to have more opportunity to respond and be responded to.

5. Encourage students to respond with more than text (e.g., podcasts, vodcasts, and wikis). Students who are already comfortable with technology and a variety of media can then be challenged as well.

of responses demonstrated by their peers, again strengthening the perception of the class as a community of practice and of blogs as potential medium for assisting in strengthening the classroom community.

\section{Closing Thoughts}

These are just a few of the suggestions we have come to based on our own experiences and analyses. While we know the field benefits from the narratives of successful teaching, we are hoping our experiences as successful instructors who were unsuccessful with technology can also benefit the field of literacy. In particular, when we studied the focus group discussions, we realized our inability to reach out to those tech-savvy students that we thought those tech-savvy students that we thought would be excited to blog regularly.

Our assumptions were problematic in a couple of ways. First, we inadvertently lumped our students together, considering all of them to be tech-savvy and anxious to spend more time on the computer to create community. Second, we now realize that the majority of the students who came to us already tech-savvy benefited little from this addition to our course, and more from the other instruction taking place. Teaching is always a humbling experience for us. Luckily, we get to take a step back, look at what we have found, and try again, hopefully learning from our mistakes.

\section{Notes}

This study was made possible by a QEP grant gifted by our university. A special thanks to David Silva, PhD, and David Purkiss for their contributions to and facilitation of our research.

\section{References}

Allen, I.E., Seaman, J., \& Garrett, R. (2007). Blending in: The extent and promise of blended education in the United States. Needham, MA: Sloan Consortium.

Alvermann, D.E. (2008). Why bother theorizing adolescents' online literacies for classroom practice and research? Journal of Adolescent \& Adult Literacy, 52(1), 8-19. doi:10.1598/ JAAL.52.1.2

Alvermann, D.E., Phelps, S., \& Gillis, V. (2006). Content area reading and literacy: Succeeding in today's diverse classrooms. New York: Pearson.

Alvermann, D.E. (2005). Adolescents and literacies in a digital world. New York: Peter Lang.

Beckett, G.H., Amaro-Jiménez, \& Beckett, K.S. (2010). Students' use of asynchronous discussions for academic discourse socialization. Distance Education, 31(3), 315-334. doi:10.1080/ 01587919.2010.513956

Creswell, J.W. (2009). Research design: Qualitative, quantitative, and mixed methods approaches (3rd ed.). Los Angeles: Sage.

Fairclough, N. (2001). Language and power (2nd ed.). London: Longman.

Gee, J.P. (1999). An introduction to discourse analysis: Theory and method. New York: Routledge.

Gorski, P.C. (2005). Multicultural education and the Internet: Intersections and integrations. Boston: McGraw Hill.

Green, T.D., Brown, A., \& Robinson, L. (2008). Making the most of the web in your classroom: A teachers' guide to blogs, podcasts, wikis, pages, and sites. Thousand Oaks, CA: Corwin.

Hubbard, R., \& Power, B. (1999). Living the questions: A guide for teacher-researchers. Portland, ME: Stenhouse.

Johnson, D. (2010). Teaching with authors' blogs: Connections, collaboration, creativity. Journal of Adolescent \& Adult Literacy, 54(3), 172-180. doi:10.1598/JAAL.54.3.2 
Kist, W. (2008). "I gave up MySpace for Lent": New teachers and social networking sites. Journal of Adult \& Adolescent Literacy, 52(3), 245-247. doi:10.1598/JAAL.52.3.7

Lave, J. (1996). Teaching, as learning, in practice. Mind, Culture, and Activity, 3(3), 149-164. doi:10.1207/s15327884mca0303_2

Lin, Q. (2008). Student satisfactions in four mixed courses in elementary teacher education program. The Internet and Higher Education, 11(1), 53-59. doi:10.1016/j.iheduc.2007.12.005

Lincoln, Y.S., \& Guba, E.G. (1984). Naturalistic inquiry. Thousand Oaks, CA: Sage.

Merriam, S.B. (Ed.). (2002). Qualitative research in practice: Examples for discussion and analysis. San Francisco: Jossey-Bass.

National Association for the Education of Young Children. (2002). NAEYC standards for early childhood professional preparation. Retrieved September 13, 2010, from www .naeyc.org/files/naeyc/file/positions/2002.pdf

Rogoff, B. (1995). Observing sociocultural activity on three planes: Participatory appropriation, guided participation, and apprenticeship. In J.V. Wertsch, P.D. Rio, \& A. Alvarez (Eds.), Sociocultural studies of mind (pp. 139-164). New York: Cambridge University Press.

Rogoff, B., \& Lave, J. (Eds.). (1984). Everyday cognition: Its development in social context. Cambridge, MA: Harvard University Press.

West, K.C. (2008). Weblogs and literary response: Socially situated identities and hybrid social languages in English class blogs. Journal of Adolescent \& Adult Literacy, 51(7), 588-598. doi:10.1598/JAAL.51.7.6
Yang, S.-H. (2009). Using blogs to enhance critical reflection and community of practice. Journal of Educational Technology $\mathcal{E}$ Society, 12(2), 11-21.

Hungerford-Kresser, Wiggins, and Amaro-Jiménez are assistant professors in the Curriculum and Instruction Department at the University of Texas, Arlington, USA; e-mailhhkresser@uta.edu; jwiggins@uta.edu; amaro@uta.edu.

\section{More to Explore}

\section{IRA Journal Articles}

- "Electronic Reading Workshop: Beyond Books With New Literacies and Instructional Technologies" by Lotta C. Larson, Journal of Adolescent \& Adult Literacy, October 2008

- "Missed Opportunities in Cyberspace: Preparing Preservice Teachers to Facilitate Critical Talk About Literature Through Computer-Mediated Communication" by Susan L. Groenke, Journal of Adolescent \& Adult Literacy, November 2008

- "Secondary Preservice Teachers Remember Their Favorite Reading Experiences: Insights and Implications for Content Area Instruction" by Peggy Daisey, Journal of Adolescent \& Adult Literacy, May 2010 
Copyright of Journal of Adolescent \& Adult Literacy is the property of International Reading Association and its content may not be copied or emailed to multiple sites or posted to a listserv without the copyright holder's express written permission. However, users may print, download, or email articles for individual use. 